\title{
Interpretation of serum parathyroid hormone concentrations in dialysis patients: what do the KDIGO guidelines change for the clinical laboratory?
}

\author{
Jean-Claude Souberbielle ${ }^{1, *}$, Etienne Cavalier $^{2}$ \\ and Guillaume Jean ${ }^{3}$ \\ ${ }^{1}$ Laboratoire d'Explorations Fonctionnelles, Hôpital \\ Necker-Enfants Malades, Paris, France and Université \\ Paris Descartes, INSERM U845, Paris, France \\ ${ }^{2}$ Department of Clinical Chemistry, University of Liège, \\ University Hospital of Liège, Liège, Belgium \\ ${ }^{3}$ Centre de Rein Artificiel, Tassin la Demi-lune, France
}

\begin{abstract}
The Kidney Disease: Improving Global Outcomes (KDIGO) have recently replaced the K/DOQI guidelines to help nephrologists in diagnosing, treating and monitoring chronic kidney disease mineral and bone disorders (CKD-MBD). Here, we comment on the KDIGO recommendations concerning the interpretation of parathyroid hormone (PTH) concentrations in dialysis patients: "In patients with CKD stage $5 \mathrm{D}$, we suggest maintaining $\mathrm{iPTH}$ in the range of approximately two to nine times the upper normal limit of the assay. We suggest that marked changes in PTH concentrations in either direction within this range prompt an initiation or change in therapy to avoid progression to concentrations outside of this range', Our comments concern the interpretation of PTH in dialysis patients, but also the more global problem of establishing normal values for PTH.

Clin Chem Lab Med 2010;48:769-74.
\end{abstract}

Keywords: chronic kidney disease; clinical guidelines; dialysis; parathyroid hormone; reference values.

\section{Introduction}

Chronic kidney disease mineral and bone disorders (CKD$\mathrm{MBD}$ ) are well known consequences of decreases in glomerular filtration rate (GFR). They include 1) anomalies in calcium, phosphorus, parathyroid hormone $(\mathrm{PTH})$, or vitamin $\mathrm{D}$ metabolism, 2) anomalies in bone turnover, bone miner-

*Corresponding author: Jean-Claude Souberbielle, Laboratoire d'Explorations Fonctionnelles, Hôpital Necker-Enfants Malades, 149 rue de Sèvres, 75015, Paris, France and Université Paris Descartes, INSERM U845, Paris, France E-mail: jean-claude.souberbielle@nck.aphp.fr Received December 14, 2009; accepted January 21, 2010; previously published online March 19, 2010 alization, bone growth and/or bone strength, and 3) extraskeletal calcification including vascular calcifications. The term renal osteodystrophy now relates only to anomalies diagnosed during the histomorphometric evaluation of a bone biopsy. Since 2003, the nephrologists relied on the K/DOQI guidelines (1) to diagnose, treat, and monitor CKDMBD. Since the publication of the K/DOQI, new information has become available, justifying an update of these recommendations. This was achieved with the Kidney Disease: Improving Global Outcomes (KDIGO) initiative, first published as a summary of a consensus conference (2), and recently (August 2009) updated as more extensive guidelines (3). Several differences between the K/DOQI and the KDIGO guidelines are the main biological parameters of calcium/ phosphorus and bone metabolism, as summarized in Table 1. We must stress that the overall level of evidence for these recommendations is low, and that the need for further research is great as emphasized by the authors of the KDIGO. However, these guidelines may help the clinical Nephrology practice, specially those nephrologists who lack the time to read (and "digest') the great amount of new, highly specialized medical and scientific literature. In the present review we aim to comment on the KDIGO recommendation concerning the interpretation of PTH serum levels in dialysis patients (stage 5D CKD patients), which states: "In patients with CKD stage 5D, we suggest maintaining iPTH levels in the range of approximately two to nine times the upper normal limit for the assay. We suggest that marked changes in PTH levels in either direction within this range prompt an initiation or change in therapy to avoid progression to levels outside of this range'". Again, as acknowledged by the KDIGO work group, the level of this recommendation is weak, based on a low level of evidence.

\section{The KDIGO PTH range and the PTH reference values}

Secondary hyperparathyroidism (SHPT) is a common feature associated with decreased GFR. The mechanism by which SHPT occurs in CKD is complex, and involves among other things hyperphosphatemia, high FGF 23 (fibroblast growth factor 23) secretion, decreased renal production of calcitriol, a shift in the calcium set-point, and skeletal resistance to PTH. SHPT can be considered an appropriate adaptative response to a decreasing GFR in order to maintain calcium/ phosphorus homeostasis. However, SHPT may have delete- 
Table 1 Differences between the K/DOQI and the KDIGO for the four main parameters of calcium/phosphorus metabolism.

\begin{tabular}{lll}
\hline & K/DOQI & KDIGO \\
\hline Serum calcium & $2.10-2.37 \mathrm{mmol} / \mathrm{L}$ & Reference range of the laboratory \\
Serum phosphate & $1.10-1.80 \mathrm{mmol} / \mathrm{L}$ & Tend toward the reference range of the laboratory \\
Serum PTH & $150-300 \mathrm{pg} / \mathrm{mL}$ & $2-9$ times the upper limit of normal \\
Serum $25 \mathrm{OH}$ vitamin D & Not recommended in CKD stage 5D & Maintain within $30-100 \mathrm{ng} / \mathrm{mL}$ \\
\hline
\end{tabular}

rious consequences on bone turnover and mineralization and, in its severe forms, may lead to osteitis fibrosa cystica. SHPT may also become autonomous, leading to tertiary (hypercalcemic) hyperparathyroidism. However, it is clear that many patients with CKD do not exhibit a sufficient increase in PTH concentrations, or have some degree of resistance to PTH (of unclear mechanism). This implies that their bone turnover is lower than expected considering their serum PTH concentrations. This corresponds to adynamic bone disease and is associated with a tendency for hypercalcemia and an increased risk of vascular calcifications. Thus, both too high and too low PTH concentrations are better avoided in patients with $\mathrm{CKD}$, leading experts to propose an optimal range for serum PTH concentrations. As mentioned above, the recommended target range for serum $\mathrm{PTH}$ in dialysis patients has changed from 150 to $300 \mathrm{pg} / \mathrm{mL}$ in the K/DOQI, to 2-9 times the upper limit of normal in the KDIGO. This raises several issues. We must remember that the K/DOQI target range for serum PTH concentrations was derived from studies performed in the late 1980s-early 1990s that compared bone biopsy data from dialysis patients to serum PTH concentrations measured with the (no longer available) Allegro Intact PTH assay (Nichols Institute Diagnostics) (4). Since then, it has been reported that any kind of bone turnover could be found for PTH values between (grossly) $100-500 \mathrm{pg} / \mathrm{mL}$ (5), with no intervention study showing a survival benefit for any range of PTH concentrations. Other studies reported that for dialysis patients, PTH concentrations are associated with mortality only for the highest concentrations (above 400-600 pg/mL) $(6,7)$. For these reasons, the K/DOQI PTH range (150-300 $\mathrm{pg} / \mathrm{mL}$ ) has been expanded in the KDIGO, corresponding for example to $130-585 \mathrm{pg} / \mathrm{mL}$ with the Allegro assay when the manufacturer's upper limit of normal of $65 \mathrm{pg} / \mathrm{mL}$ is considered. Another point requiring discussion is why the KDIGO propose a target PTH range based on multiples of the upper normal limit, rather than absolute concentrations, such as in the K/DOQI. To understand this, the inter-method variability in PTH measurements should be considered (8). Indeed, while the K/DOQI proposed the same PTH target range whatever the assay used, the PTH concentration in a given sample may vary by a factor $>2$, depending on the assay used. A comparison of PTH assays available in France during 2005 found that the PTH concentration in a given sample might be either below or above the K/DOQI target range using the assays that produced the lowest and the highest concentrations, respectively. This could potentially cause opposite diagnostic/therapeutic conclusions (8). Thus, what may be not clinically relevant when assay-specific clinical cut-offs are used, may become highly problematic when the same clinical cut- off for a diagnostic/therapeutic decision is used, whatever the assay method used. Since the standardization of PTH assay methods is highly difficult to achieve due to the lack of an international standard made of recombinant 1-84 PTH, and also to the variable cross-reactivity of PTH fragments to the different assays, the proposition by the KDIGO work group to use a target range for serum PTH based on the upper limit of the normal values is a pragmatic way to overcome this problem of inter-method variability in PTH assays. However, we have some concerns that necessitate discussion about PTH reference values. Reference values for serum PTH concentrations are obtained by measuring PTH in a reference population of apparently healthy subjects. Exclusion criteria for this population are extremely important and correspond to any cause of altered PTH secretion, including vitamin D insufficiency. This last point is important, because according to most reports (9), vitamin D insufficiency is very frequent in the general population and should therefore be prevalent in an otherwise apparently healthy group recruited to establish PTH reference values. However, excluding vitamin D deficient subjects from the reference group requires measuring 25-hydroxy vitamin D (25OHD) concentrations beforehand in all subjects, a practice which complicates establishment of PTH reference values, and which was not considered in most studies that provided serum PTH reference values for different immunoassays (10-12). However, we have demonstrated that excluding subjects with low serum 25OHD concentrations from a reference population decreased the upper normal limit for serum PTH by $25 \%-35 \%$, depending on the assay being considered and compared to the initial reference populations [e.g., $46 \mathrm{pg} / \mathrm{mL}$ instead of $65 \mathrm{pg} / \mathrm{mL}$ with the Allegro intact PTH assay (13)]. As a result of this example, the KDIGO target range for the Allegro assay would have been $130-585 \mathrm{pg} / \mathrm{mL}$ using the manufacturer's upper normal limit of $65 \mathrm{pg} / \mathrm{mL}$, whereas it would have been $92-414 \mathrm{pg} / \mathrm{mL}$ using our proposed upper limit of $46 \mathrm{pg} / \mathrm{mL}$. Thus, for a given PTH assay, the normal values, and consequently the KDIGO target range may vary significantly, depending on the reference population that has been recruited, and especially whether vitamin D status has been considered. In addition, several other determinants of PTH concentrations should also be considered including age, GFR, calcium intake, race, and body mass index (BMI), as suggested by the expert panel who published the last recommendations for the diagnosis of asymptomatic primary hyperparathyroidism (14). Thus, waiting for more definitive studies (i.e., establishment of PTH reference values for all the available assays, using the same extensive population of vitamin D-replete normal subjects, with stratification according to age, GFR, calcium intake, ethnicity...), nephrologists 
will need to rely on the reference range provided by the laboratory, even if the reference population is not clearly described. As an illustration of this problem, we reported recently in this journal a systematic $30 \%$ difference between PTH concentrations measured with the Roche Diagnostics Elecsys assay and the Abbott Diagnostics Architect assay (higher values with the Architect assay). However, the manufacturer's upper limit of normal for these two kits is similar (65 pg/mL and $68 \mathrm{pg} / \mathrm{mL}$ for the Elecsys and the Architect assay, respectively), suggesting that the reference populations for these two kits differed significantly in terms of inclusion criteria (15).

\section{Interpretation of a serum PTH in dialysis patients}

As indicated above, the recommendation of the KDIGO guidelines is to consider the evolution of PTH concentrations in a given patient (rather than its absolute concentration) to initiate therapeutic changes. Furthermore, the KDIGO group acknowledges that the concentration of other parameters, such as serum calcium, phosphorus, 25OHD, and alkaline phosphatase, and their evolution must be considered for the interpretation of serum PTH concentrations and for therapeutic decisions. This seems obvious, but was not clearly stated in the K/DOQI guidelines. In practice, a PTH concentration in the middle of the recommended range should not result in the same therapeutic considerations if the previous concentrations were above or below the target range (as illus- trated by the two examples in Table 2), or, in case of stability, when it is associated to high/normal high or low/normal low serum calcium and/or phosphorus (as illustrated by other examples in Table 3). Schematically, an increase in PTH concentrations toward the upper limit of the recommended range should induce treatment to decrease PTH, while decreases will favor stopping or decreasing such treatment. However, for a given high or high normal PTH value, PTH-lowering treatment should be preferably a calcimimetic when high or high normal calcium concentrations are present, and an active vitamin D compound in cases with low or low normal serum calcium concentrations.

Finally, two other points deserve brief comment. First, contrary to the K/DOQI, the KDIGO recommendation is to correct vitamin D deficiency/insufficiency in dialysis patients. This entails measuring serum 25OHD concentrations and is a prerequisite in cases with high PTH before treating with active vitamin D or a calcimimetic. Indeed, numerous studies suggest that this supplementation which is simple, cheap, and very well tolerated may be beneficial, even for patients undergoing dialysis (3). Indeed, besides its potential pleiotropic effects (16), vitamin D supplementation, moderately, but significantly, reduces PTH concentrations in dialysis patients (17). Second, we welcome the proposition by the KDIGO to add the measurement of total alkaline phosphatase, and of the bone isoenzyme when total alkaline phosphatase is abnormal, into the panel of bone-related parameters. Indeed, while PTH has important effects on bone turnover, serum PTH concentrations cannot be considered as a surrogate bone marker. As indicated above, any bone turn-

Table 2 Dynamic interpretation of the biological results of two dialysis patients (case 1 and case 2) with the same PTH concentration $(300 \mathrm{pg} / \mathrm{mL})$, but a very different physiological evolution.

\begin{tabular}{|c|c|c|c|c|}
\hline & Baseline & 3 months & 6 months & $\begin{array}{l}\text { PTH-lowering } \\
\text { treatment }\end{array}$ \\
\hline \multicolumn{5}{|l|}{ Case 1} \\
\hline $\begin{array}{l}\text { PTH, pg/mL } \\
(10-65 \mathrm{pg} / \mathrm{mL})\end{array}$ & 878 & 478 & 300 & \\
\hline $\begin{array}{l}\text { Serum calcium, } \mathrm{mmol} / \mathrm{L} \\
(2.20-2.60 \mathrm{mmol} / \mathrm{L})\end{array}$ & 2.36 & 2.45 & 2.5 & $\downarrow$ \\
\hline $\begin{array}{l}\text { Serum phosphate, } \mathrm{mmol} / \mathrm{L} \\
(0.85-1.5 \mathrm{mmol} / \mathrm{L})\end{array}$ & 1.6 & 1.7 & 1.8 & \\
\hline $\begin{array}{l}\text { Total alkaline phosphatase, IU/L } \\
(30-130 \text { IU/L) }\end{array}$ & 220 & 156 & 108 & \\
\hline \multicolumn{5}{|l|}{ Case 2} \\
\hline $\begin{array}{l}\text { PTH, pg/mL } \\
(10-65 \mathrm{pg} / \mathrm{mL})\end{array}$ & 69 & 187 & 300 & \\
\hline $\begin{array}{l}\text { Serum calcium, } \mathrm{mmol} / \mathrm{L} \\
(2.20-2.60 \mathrm{mmol} / \mathrm{L})\end{array}$ & 2.5 & 2.45 & 2.29 & $\uparrow$ \\
\hline $\begin{array}{l}\text { Serum phosphate, } \mathrm{mmol} / \mathrm{L} \\
(0.85-1.5 \mathrm{mmol} / \mathrm{L})\end{array}$ & 1.9 & 1.7 & 1.5 & \\
\hline $\begin{array}{l}\text { Total alkaline phosphatase, IU/L } \\
(30-130 \text { IU/L) }\end{array}$ & 40 & 78 & 159 & \\
\hline
\end{tabular}

In case 1, PTH decreases over the 6-month period with a concomitant decrease in alkaline phosphatase activity and an increase in serum calcium. To avoid adynamic bone disease, PTH-lowering treatments will be decreased. In case 2, PTH increases over the same period while serum calcium and phosphate both decrease. To prevent severe secondary hyperparathyroidism, PTH-lowering treatments will be increased by the nephrologists. These two cases illustrate the KDIGO recommendation to take into account the evolution of the biological parameters rather than an absolute value. PTH-lowering treatments include calcium (dietary, supplemental, or through dyalisate), active vitamin D compound or cinacalcet. 
Table 3 Examples of possible interpretations of the same serum PTH concentration (arbitrarily $300 \mathrm{pg} / \mathrm{mL}$ ) measured in a dialysis patient with respect to the other parameters of calcium/phosphorus metabolism.

\begin{tabular}{|c|c|c|c|c|c|}
\hline Suspicion of... & $\begin{array}{l}\text { Serum calcium, } \\
\mathrm{mmol} / \mathrm{L} \\
(2.20-2.60 \\
\mathrm{mmol} / \mathrm{L})\end{array}$ & $\begin{array}{l}\text { Serum phosphate, } \\
\mathrm{mmol} / \mathrm{L} \\
(0.85-1.45 \\
\mathrm{mmol} / \mathrm{L})\end{array}$ & $\begin{array}{l}\text { Serum } \\
\text { PTH, pg/mL } \\
(10-65 \\
\mathrm{pg} / \mathrm{mL})\end{array}$ & $\begin{array}{l}\text { Serum } \\
25 \mathrm{OHD}, \mathrm{nmol} / \mathrm{L} \\
(75-200 \\
\mathrm{nmol} / \mathrm{L})\end{array}$ & $\begin{array}{l}\text { Serum bone alkaline } \\
\text { phosphatase, } \mu \mathrm{g} / \mathrm{L} \\
(5-20 \mu \mathrm{g} / \mathrm{L})\end{array}$ \\
\hline $\begin{array}{l}\text { Moderate secondary } \\
\text { hyperparathyroidism }\end{array}$ & 2.15 & 1.7 & 300 & 12 & 27 \\
\hline Adynamic bone & 2.5 & 1.4 & 300 & 28 & 7 \\
\hline $\begin{array}{l}\text { Tertiary } \\
\text { hyperparathyroidism }\end{array}$ & 2.65 & 2.0 & 300 & 39 & 35 \\
\hline
\end{tabular}

Normal values are in brackets.

over may be associated with PTH concentrations ranging from 100 to $500 \mathrm{pg} / \mathrm{mL}$ (5). It must be remembered that bone turnover is quite a slow process, which can take a few weeks, in cases of high bone turnover, to a few months, or years in cases of adynamic bone disease, whereas secretion of PTH is a very quick process (minutes) in response to variations of ionized calcium. Thus, an isolated measurement of serum PTH is unlikely to provide a valid representation of bone turnover, except in cases with extremely low or high values.

\section{Choosing a PTH assay}

The KDIGO recommend that "...clinical laboratories inform clinicians of the actual assay method in use and report any change in methods, sample source (plasma or serum), and handling specifications...", The choice of a PTH assay is thus not only of interest for the laboratory, but also for the clinician. PTH is an 84 amino-acid peptide. For PTH calcemic effects to be exerted, the very first amino-acids of the N-terminal end of the hormone must be present. The socalled 'intact', PTH assays (second-generation PTH assays) are used by most laboratories worldwide. It is now well established that in addition to 1-84 PTH, the secondgeneration PTH assays measure "N-truncated" fragments (such as 7-84 PTH) that have been shown in experimental studies to exert effects that are opposite to those of 1-84 PTH (18). Since 1999, third-generation PTH assays that do not cross-react with 7-84 PTH are available (19). Although highly interesting in better understanding PTH physiology, these assays have not been found to provide more clinically meaningful information than the second-generation PTH assays when compared to bone biopsy data (20-22). Adding to this finding is the fact that the only currently available third-generation assay is an immuno-radiometric assay, available to a limited number of laboratories only and the KDIGO working group did not recommend its use (3). However, we believe that for the third-generation assays, further studies are needed to evaluate the diagnostic sensitivity for altered bone turnover better as well as their ability to predict other outcomes, such as mortality, as suggested by one study (23), or vascular calcification. This is more feasible since the new fully automated third-generation assays will soon become available. Furthermore, since the third-generation assays pro- duce lower values than the second-generation PTH assays, their use was not possible with the KDOQI target PTH ranges or able to correct PTH concentrations using a specific factor (24) or modify the target PTH range; two solutions that are far from perfect. This is no longer a problem with the KDIGO as the new target range depends on the upper limit of normal for a given PTH assay, including the thirdgeneration assays. Finally, preanalytical considerations must be taken into account, specially the nature of the blood sample. Significant differences in PTH concentrations measured in serum and EDTA plasma have been reported with some assays, such as the Immulite PTH assay (25-27). To account for these differences, the manufacturer proposes normal values that are different for serum and EDTA plasma, with the consequent differences for the KDIGO target range for dialysis patients. Thus, it is important that the laboratory gives the nephrologist clear indications concerning the nature of the specimen type to be used for PTH measurements, as requested by the KDIGO. Although there is no consensus, we prefer serum for practical reasons, such as the possibility of measuring calcium in serum, but not in EDTA plasma, and the necessity for filling the EDTA tube, but not the tube for collection of serum (28). However, as PTH collected in EDTA has been reported to be slightly more stable than PTH in serum at room temperature $(25,29)$, it is important to standardize the storage of the serum samples if not assayed immediately. Our recommendation is to freeze the serum at $-20^{\circ} \mathrm{C}$ within $4-6 \mathrm{~h}$ of blood collection. Special cases can occur when a blood sample is collected in the evening at a dialysis centre and sent to the laboratory the next morning. We demonstrated previously that if the primary tube is a gel type serum tube and is centrifuged without opening in the dialysis centre (assuming that the dialysis center has a centrifuge), measurement of serum PTH may be delayed by at least $18 \mathrm{~h}$ if the primary tube is maintained at $4^{\circ} \mathrm{C}(30)$. Serum seems also preferable when samples have to be stored for long periods of time at $-80^{\circ} \mathrm{C}$, such as for research studies (31).

\section{Conclusions}

The recommended target range for serum PTH in dialysis patients has changed from 150 to $300 \mathrm{pg} / \mathrm{mL}$ in the K/DOQI, 
to 2-9 times the upper limit of normal in the KDIGO. While this will minimize the problem of inter-method variability of PTH measurement, this also raises questions regarding the establishment of normal values for serum PTH, and especially the definition of the reference population. The good news is that this will reinforce the dialogue between nephrologists and clinical chemists.

\section{Conflict of interest statement}

Authors' conflict of interest disclosure: The authors stated that there are no conflicts of interest regarding the publication of this article.

Research funding: None declared.

Employment or leadership: None declared.

Honorarium: None declared.

\section{References}

1. K/DOQI clinical practice guidelines for bone metabolism and disease in chronic kidney disease. Am J Kidney Dis 2003;42: S1-201.

2. Moe S, Drüeke T, Cunningham J, Goodman W, Martin K, Olgaard K, et al. Definition, evaluation, and classification of renal osteodystrophy: a position statement from Kidney Disease: Improving Global Outcomes (KDIGO). Kidney Int 2006; 69:1945-53.

3. Kidney Disease: Improving Global Outcomes (KDIGO) CKDMBD work group. KDIGO clinical practice guideline for the diagnosis, evaluation, prevention, and treatment of Chronic Kidney Disease-Mineral and Bone Disorder (CKD-MBD). Kidney Int 2009;6:S1-130.

4. Sherrard DJ, Hercz G, Pei Y, Maloney NA, Greenwood C, Manuel A, et al. The spectrum of bone disease in end-stage renal failure: an evolving disorder. Kidney Int 1993;43:436-42.

5. Barretto FC, Barreto DV, Moyses RM, Neves KR, Canziani ME, Dralbe SA, et al. K/DOQI-recommended intact PTH levels do not prevent low turnover bone disease in hemodialysis patients. Kidney Int 2008;73:771-7.

6. Block GA, Klassen PS, Lazarus JM, Ofsthun N, Lowrie EG. Mineral metabolism, mortality, and morbidity in maintenance hemodialysis. J Am Soc Nephrol 2004;15:2208-18.

7. Kalantar-Zadeh K, Kuwae N, Regidor DL, Kovesdy CP, Kilpatrick RD, Shinaberger CS, et al. Survival predictability of time-varying indicators of bone disease in maintenance hemodialysis patients. Kidney Int 2006;70:771-780.

8. Souberbielle JC, Boutten A, Carlier MC, Chevenne D, Coumaros G, Lawson-Body E, et al. Inter-method variability in PTH measurement: implication for the care of CKD patients. Kidney Int 2006;70:345-50.

9. Mithal A, Wahl A, Bonjour JP, Burckhardt P, Dawson-Hughes B, Eisman JA, et al. Global vitamin D status and determinants of hypovitaminosis D. Osteoporos Int 2009;20:1807-20.

10. Nussbaum S, Zahradnik R, Lavigne J, Brennan G, NozawaUng K, Kim L, et al. Highly sensitive two-site immunoradiometric assay of parathyrin, and its clinical utility in evaluating patients with hypercalcemia. Clin Chem 1987;33:1364-7.

11. Blind E, Schmidt-Gayk H, Scharla S, Flentje D, Fischer S, Göhring U, et al. Two-site assay of intact parathyroid hormone in the investigation of primary hyperparathyroidism and other disorders of calcium metabolism compared with a mid-region assay. J Clin Endocrinol Metab 1988;67:353-60.

12. Endres D, Villanueva R, Sharp Jr C, Singer F. Immunochemiluminometric and immunoradiometric determinations of intact and total immunoreactive parathyrin: performance in the differential diagnosis of hypercalcemia and hypoparathyroidism. Clin Chem 1991;37:162-8.

13. Souberbielle JC, Cormier C, Kindermans C, Gao P, Cantor T, Forette $\mathrm{F}$, et al. Vitamin D status and redefining serum parathyroid hormone reference range. $\underline{\mathrm{J} \text { Clin Endocrinol Metab }}$ 2001;86:3086-90.

14. Eastell R, Arnold A, Brandi ML, Brown EM, D’Amour P, Hanley DA, et al. Diagnosis of asymptomatic primary hyperparathyroidism: proceedings of the third international workshop. J Clin Endocrinol Metab 2009;94:340-50.

15. Monge M, Jean G, Bacri JL, Masy E, Joly D, Souberbielle JC. Higher parathyroid hormone (PTH) concentrations with the architect PTH assay than with the Elecsys assay in hemodialysis patients, and a simple way to standardize these two methods. Clin Chem Lab Med 2009;47:362-6.

16. Cavalier E, Delanaye P, Chapelle JP, Souberbielle JC. Vitamin D: current status and perspectives. Clin Chem Lab Med 2009; 47:120-7.

17. Jean G, Souberbielle JC, Chazot C. Monthly cholecalciferol administration in haemodialysis patients: a simple and efficient strategy for vitamin D supplementation. Nephrol Dial Transplant 2009;24:3799-805.

18. Slatopolsky E, Finch J, Clay P, Martin D, Sicard G, Gao P, et al. A novel mechanism for skeletal resistance in uremia. Kidney Int 2000;58:753-61.

19. Gao P, Scheibel S, D'Amour P, John M, Rao S, Schmidt-Gayk $\mathrm{H}$, et al. Development of a novel immunoradiometric assay exclusively for biologically active whole parathyroid hormone 1-84: implication for improvement of accurate assessment of parathyroid function. J Bone Miner Res 2001;16:605-14.

20. Coen G, Bonucci E, Ballanti P, Balducci A, Calabria S, Nicolai G, et al. PTH 1-84 and PTH " $7-84$ "' in the non-invasive diagnosis of bone disease. Am J Kidney Dis 2002;40:348-54.

21. Salusky I, Goodman W, Kuizon B, Lavigne J, Zahranik R, Gales B, et al. Similar predictive value of bone turnover using first- and second-generation immunometric PTH assays in pediatric patients treated with peritoneal dialysis. Kidney Int 2003; 63:1801-8.

22. Lehmann G, Stein G, Hüller M, Schemer R, Ramakrishnan K, Goodman W. Specific measurement of PTH (1-84) in various forms of renal osteodystrophy (ROD) as assessed by bone histomorphometry. Kidney Int 2005;68:1206-14.

23. Melamed M, Eustace J, Plantinga L, Jaar B, Fink N, Parekh R, et al. Third-generation parathyroid hormone assays and allcause mortality in incident dialysis patients: the CHOICE study. Nephrol Dial Transplant 2008;23:1650-8.

24. Souberbielle JC, Roth H, Fouque D. Parathyroid measurement in CKD. Kidney Int 2010;77:93-100.

25. Joly D, Drueke T, Alberti C, Houillier P, Lawson-Body E, Martin KJ, et al. Variation in serum and plasma PTH levels in second-generation assays in hemodialysis patients: a cross-sectional study. Am J Kidney Dis 2008;51:987-95.

26. Twoney PJ, Whitlock T, Pledger DR. Differences between serum and plasma for intact parathyroid hormone measurement in patients with chronic renal failure in routine clinical practice. J Clin Pathol 2005;58:1000-1.

27. Holmes DT, Levin A, Forer B, Rosenberg F. Preanalytical influences on DPC IMMULITE 2000 intact PTH assays of plasma and serum from dialysis patients. Clin Chem 2005;51:915-7. 
28. Glendenning P, Musk A, Taranto M, Vasikaran S. Preanalytical factors in the measurement of intact parathyroid hormone with the DPC Immulite assay. Clin Chem 2002;48:566-7.

29. Cavalier E, Delanaye P, Carlisi A, Krzesinsky JM, Chapelle JP. Stability of parathyroid hormone in samples from hemodialysis patients. Kidney Int 2007;72:370-2.

30. Parent X, Alenabi F, Brignon P, Souberbielle JC. Delayed meas- urement of PTH in patients with CKD: storage of the primary tube in the dialysis unit, which temperature? Which kind of tube? [article in French]. Nephrol Ther 2009;5:34-40.

31. Cavalier E, Delanaye P, Hubert P, Krzesinski JM, Chapelle JP, Rozet E. Estimation of the stability of parathyroid hormone when stored at $-80^{\circ} \mathrm{C}$ for a long period. Clin J Am Soc Nephrol 2009;4:1988-92. 